\title{
ESTATÍSTICA E EMPREGO DE NOVAS TECNOLOGIAS EM SEGURANÇA PÚBLICA: MÉTODO E CONTROLE CIENTÍFICO SOBRE A POLÍCIA
}

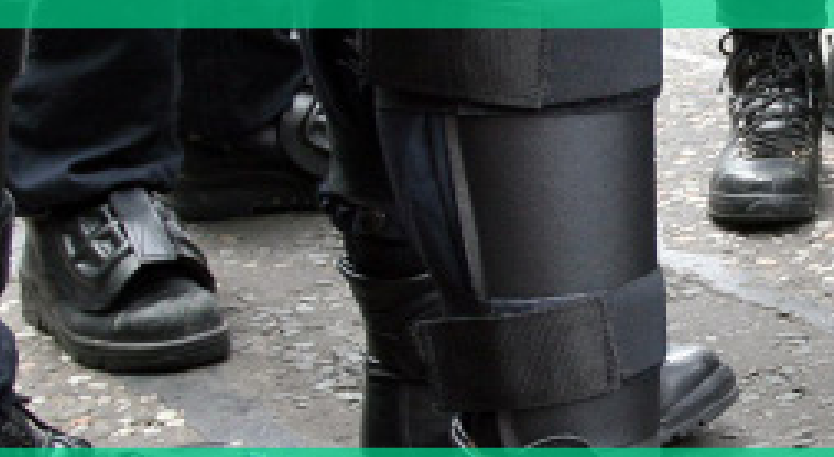

\section{Nélio Reis Biá Nascimento}

Bacharel em Direito (UNIVALI/SC). Bacharel em Administração Pública (UDESC). Mestre em Segurança Pública, Direitos Humanos e Cidadania pela Universidade Estadual de Roraima- UERR nelio.biah@gmail.com

\section{Anderson Morais de Oliveira}

Bacharel em Segurança Pública pela Universidade Estadual de Roraima - UERR, Especialista em Segurança Pública pela Universidade Federal de Roraima - UFRR, Mestre em Segurança Pública, Direitos Humanos e Cidadania pela Universidade Estadual de Roraima - UERR. anderson.moraes.oliveira@gmail.com

\section{RESUMO}

Objetiva-se com este artigo, demonstrar a importância da análise estatística, das novas tecnologias e dos indicadores de desempenho para os órgãos de segurança pública, inclusive, como facilitador das execuções das atividades desempenhadas pelos referidos órgãos governamentais, bem como para a devida prestação de contas do serviço realizado em prol da sociedade, que, como corresponsável pela segurança pública tem o direito de saber de que forma os recursos investidos em segurança pública estão sendo aplicados pela Administração Pública. Da mesma forma, o artigo denota a importância do uso das ferramentas de geoprocessamento para mapeamento da criminalidade, bem como para o adequado emprego das forças de segurança pública no combate à criminalidade, assim, foi utilizada a pesquisa bibliográfica, de caráter descritivo, através do método indutivo.

Assim, observou-se que a utilização da estatística e das novas tecnologias é de extremamente relevante para a obtenção de melhores resultados relativamente aos órgãos do sistema de segurança pública.

Palavras-Chaves: Segurança Pública. Criminalidade. Estatística. Accountability. Geoprocessamento.
The objective of this article is to demonstrate the importance of statistical analysis, new technologies and performance indicators for public security agencies, including as a facilitator of the execution of the activities carried out by said government agencies, as well as for the adequate provision of accounts of the service performed for the benefit of society, which, as co-responsible for public security, has the right to know how the resources invested in public security are being applied by the Public Administration. Likewise, the article shows the importance of the use of geoprocessing tools for mapping crime, as well as for the adequate use of public security forces in the fight against crime, thus, a descriptive bibliographical inductive method.

Thus, it was observed that the use of statistics and new technologies is extremely relevant to obtain better results regarding the organs of the public security system.

Keywords: Public Security. Crime. Statistic. Accountability. Geoprocessing. 


\section{INTRODUÇÃO}

A evolução da gestão pública no Brasil e no mundo tem destacado cada vez mais a importância de pautar a gestão das ações públicas em função dos resultados alcançados, bem como em termos das ações executadas, dos recursos gastos e dos impactos daquelas ações.

Na área de segurança pública, no Brasil, o uso de sistemas de indicadores de desempenho para efetivar o monitoramento dos resultados das ações executadas e o emprego de estudos estatísticos e tecnologias de geoprocessamento ainda estão em seus passos iniciais.

Nesse diapasão, observa-se que são poucos os Estados que se utilizam destas ferramentas de gestão, igualmente, verifica-se também que o uso prático destas ferramentas ainda é bastante precário.

Acredita-se que um dos principais fatores que ocasionam a dificuldade de implantação desses e de outros sistemas no Brasil seja a falta de obrigação legal e moral direcionada aos gestores públicos.

Observa-se a permissividade dos Estados brasileiros, que por vezes, além de não fiscalizarem adequadamente os gestores, sequer os impõem o dever de que estes prestem contas dos resultados alcançados pelas suas ações, ou seja, promovam a accountability.

Desta forma, buscar-se-á demonstrar algumas dessas ferramentas, discorrendo sobre suas origens, e focando naquelas que têm sido implantadas com sucesso pelos órgãos de Segurança Pública em alguns Estados da Federação.

Sendo assim, adotou-se a pesquisa bibliográfica, ou de fontes secundárias, nos moldes apresentados por Lakatos e Marconi (2003, p. 183), pois, "sua finalidade é colocar o pesquisador em contato direto com tudo o que foi escrito, dito ou filmado sobre determinado assunto" eis que como elucida Manzo (1971, p. 32) tal pesquisa "oferece meios para definir, resolver, não somente problemas já conhecidos, como também explorar novas áreas onde os problemas não se cristalizaram suficientemente".

Adotou-se o caráter descritivo porque "com base em seus objetivos, acabam servindo mais para proporcionar uma nova visão do problema, o que as aproxima das pesquisas exploratórias".(GIL, 2009, p. 32).

Em relação ao método adotou-se o indutivo, tendo em vista que nos permite "construir estruturas lógicas, por meio do relacionamento entre antecedente e consequente, entre hipótese e tese, entre premissas e conclusão" (CERVO; BERVIAN; SILVA, 2007, p. 46).

Visando facilitar uma melhor compreensão por parte do leitor, este trabalho foi segmentado da seguinte forma: revisão de literatura que embasa a análise; a estatista em se tratando se segurança pública; o uso de indicadores na avaliação de desempenho; a importância do geoprocessamento e, por fim, a discussão dos resultados e considerações finais.

\section{ESTATÍSTICA EM SEGURANÇA PÚBLICA: CONTANDO CRIMES E CRIMINOSOS}

\section{Matrizes estatística \\ históricas \\ da}

Seja como for, a primeira das matrizes fundadoras do pensamento estatístico pode ser identificada, por conseguinte, nas preocupações de administração dos negócios do Estado, na Alemanha do século XVII. (BRASIL, 2009).

Nesse contexto estava permeada pelo caráter descritivo e taxionômico, ou seja, tentando classificar os fenômenos e as populações em categorias úteis à gestão de políticas estatais.

Segundo Desrosières, na tradução de Schwartzman(1996, p. 175), "ela apresenta ao príncipe ou ao funcionário responsável um 
quadro para a organização das informações multiformes disponiveis sobre um Estado, ou seja, uma nomenclatura dotada de uma lógica de inspiração aristotélica".

Essa forma foi codificada, por volta de 1660, por Cornring (1606-1681), e, transmitida mais tarde, ao longo de todo o século XVIII, pela Universidade de Gottingen, através de sua "escola estatística", notadamente, por Achenwall (1719-1772), reconhecido como o criador da palavra "estatística", bem como depois por seu sucessor na cadeira de estatística, Schlözer (1735-1809).

Em seu "Tratado de Estatística", Schlözer,foi o primeiro dessa corrente a recomendar a utilização de números precisos em vez de indicações expressas em termos literários, sem, no entanto, o fazer com frequência, ele próprio.

Uma formulação de Schlözer é significativa da tendência predominantemente estruturalista e sincrônica da estatística alemã: "a estatística é a história imóvel, a história é a estatística em marcha" (DESROSIĖRES, apudSCHWARTZMAN, 1996, p. 38).

A estatística, na tradição alemã, tinha a ambição de conhecer e sintetizar toda a sociedade humana mediante o esquadrinhamento de todos os seus traços constitutivos (aspectos sobre saúde ou questões espaciais, geográficos, entre outros). Tinha, ainda, a dimensão espacial e/ou territorial como fundamental e os produtos dessa abordagem eram fortemente empíricos, pouco explicativos e, muitas vezes, de natureza literária. (BRASIL, 2009). A s s i m , desenvolveram-se princípios da organização dos conhecimentos, das nomenclaturas, dos instrumentos de comparação de dados, tais como: quadros cruzados de critérios de avaliação de estados ou regiões (MARTIN, 2001).

No tocante às nomenclaturas, temse que esse desenvolvimento metodológico implicou num quadro classificatório amplo, organizado sob o ponto de vista "estatal" e baseado nas quatro "causas" da lógica aristotélica, pelas quais há uma subdivisão de objetivos da produção de informações.

A primeira delas seria guiada por um enfoque "material", no qual o Estado preocupa-se em descrever o território e a sua população como elementos que lhes dão substância.

A segunda causa seria de natureza "formal", cuja preocupação se dá com o conjunto normativo de uma determinada sociedade, ou seja, com sua legislação e constituição.

Sob o enfoque da terceira causa estaria o aspecto "finalístico" da ação do Estado como, por exemplo, questões militares, de segurança e justiça e de tributação.

Por fim, a quarta causa lógica que move a atuação do Estado seria a dimensão de "eficiência", na medida em que o foco da produção de dados seria sobre como monitorar a forma através da qual o Estado administra seus recursos disponíveis nas várias esferas de poder e de governo.

Dessa forma, essas quatro causas funcionariam como elos entre, de um lado, a construção de equivalências necessárias à soma de unidades como uma operação aritmética e, de outro, a coalizão de forças numa força superior.

Em ambos os processos, revela-se central a existência de elementos "portavozes" que ajudem a traduzir os sentidos assumidos pelos dados estatísticos e suas classes de equivalência (DESROSIĖRES, 1998).

Significa dizer, assim, que a existência de um quadro classificatório permitiu que a matriz alemã da estatística construísse modelos de tradução e compatibilização das inúmeras maneiras de atuação dos estados e cidades que compunham o império alemão. Dessa forma, era necessário discutir como um fenômeno social seria chamado em cada um dos locais e, ainda, como seria contado e agregado.

Nesse diapasão, os parâmetros 
de classificação e comparação foram fundamentais à discussão alemã; nas palavras de Desrosières, "esses cálculos eram apresentados como métodos práticos para solucionar problemas concretos" (1998, p. 24).

Eles se originam da preocupação com o modo através do qual o soberano irá classificar e gerir a economia e cuidará dos conteúdos políticos que movem a produção do saber do soberano, nos quais as estatísticas assumem papéis proeminentes na operação dos discursos de poder.

Para Lima (2001):

Tal preocupação será trazida ao primeiro plano e vai revelar que, mais do que isentos, os números e as formas como eles estão organizados respondem às dinâmicas das disputas de poder em torno das regras sobre como e sobre quem governa: eles são instrumentos de construção de discursos de verdade que almejam a objetividade e a legitimidade enquanto pressupostos; são resultados de múltiplos processos sociais de contagem, medição e interpretação de fatos e, portanto, dependem da circulação do poder para se reproduzirem. (p. 27).

Assim, a análise sociológica das estatísticas exige que interpretações, significados e segredos sejam assumidos como elementos de compreensão da produção e utilização de dados estatísticos.

Em termos históricos, em 1756, a Alemanha e a Inglaterra criaram 0 primeiro organismo oficial de estatística, posteriormente, na França, em 1784, Necker propôs a criação de um Bureau Central de Pesquisa e Ensino, que, por sua vez, tinha atribuições bem definidas e era "encarregado de recolher todas as informações de ordem econômica, social e demográfica". (1784, p. 23)

Um pouco antes de 1800, François de Neufchâteau lançou as premissas de um serviço desenvolvido de estatística (sobretudo com a criação de uma cadeira de estatística no Collège de France).

Em 1800, Lucien Bonaparte criou o Bureau de Statistique, ligado ao Ministério do Interior (MARTIN, 2001), assim, pouco a pouco, o público foi associado e informado: desde então as estatísticas não constituem mais um "espelho" para o príncipe e seus administradores, mas um espelho da nação para a nação, ou um "espelho da sociedade para a sociedade" (MARTIN, 2001, p. 24).

Condensando todo 0 entendimento já apresentado, Cretella Júnior (1985) já salientava o seguinte:

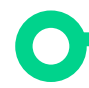

A atividade da polícia administrativa é multiforme, imprevisivel, não podendo estar limitada em todos os setores em que deve desdobrar-se. Sendo infinitos os recursos de que lança mão o gênero humano, a polícia precisa intervir sem restrições, no momento oportuno, pois que sua ação é indefinida como a própria vida, não sendo possivel aprisioná-la em fórmulas, motivo por que certa flexibilidade ou a livre escolha dos meios é inseparável da polícia. (p. 06)

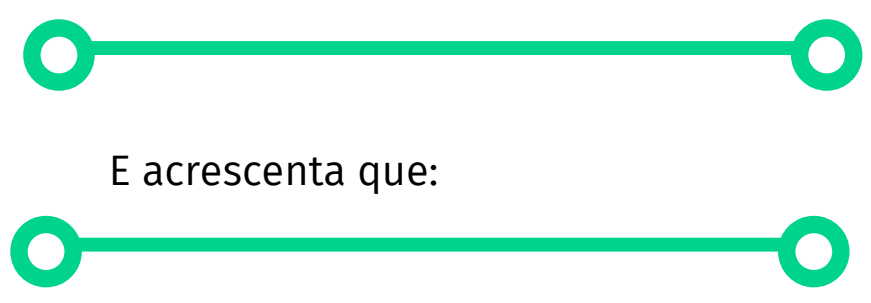

No conceito de polícia administrativa, está presente a noção de ordem pública, não a de infração. Tem por finalidade a polícia administrativa a manutenção da ordem pública, independentemente da repressão das infrações. (CRETELLA JÚNIOR, 1985, p. 06)

\section{. \\ As estatísticas na perspectiva de Foucault}

Em uma publicação editada por Grahan Burchell, Colin Gordon e Peter Miller, intitulada The Foucault Effect, Studies in Governmentality, o filósofo Ian Hacking escreve um capítulo sobre como é possivel fazer a história das estatísticas a partir da perspectiva de Foucault.

Em seu estudo, Hacking nota que, para Foucault, as estatísticas são parte dos 
mecanismos e da tecnologia de poder do Estado Moderno, nascido no século XIX em substituição ao modelo familiar de governo, e são utilizadas no processo de controle da população. (LIMA, 2001).

Significa dizer que a síntese das tradições alemã e inglesa de produção de estatísticas ocorre simultaneamente à transformação/consolidação do modelo de Estado e é amalgamada pela procura da "governamentalidade", das táticas de governo que permitem definir a cada instante o que deve ou não competir ao Estado, o que é público ou privado, o que é ou não estatal (HACKING,1992).

Esse novo modelo de Estado transforma a população em um fim, e, em um instrumento de governo, pois há uma preocupação em "geri-la em profundidade, minuciosamente, no detalhe"; há preocupação com dispositivos de vigilância e disciplina da população.

Novos campos do saber são, então, estruturados para responder às demandas postas. Não por acaso, Martin (2001) afirma que as estatísticas criminais tenham, no século XIX, permitido, senão contribuído, para o nascimento da sociologia criminal e da criminologia na Europa - por certo, como veremos, não no Brasil, onde a criminologia foi "colonizada" pelo positivismo jurídico.

Já em Vigiar e Punir, Foucault, dá a indicação que o século XIX elegeu a delinquência como uma das engrenagens do poder, correspondendo a uma mutação radical na produção discursiva sobre criminalidade e uma nova mecânica do poder, que não diz mais respeito exclusivamente à lei e à repressão, mas que dispõe de uma riqueza estratégica na medida em que investe sobre o corpo humano, não para supliciá-lo, mas para adestrá-lo; para lhe explorar o máximo de suas potencialidades, tornando-o politicamente dócil e economicamente produtivo.

Mais, uma mecânica do poder disciplinar - que reclama registro contínuo de conhecimento, ou seja, tudo o que esteja às suas voltas é exercido pelo poder e produz saber.

Trata-se, portanto, de uma forma de poder que se opõe ao modelo da soberania:

[...] em vez de orientar a pesquisa sobre o poder para o âmbito do edifício jurídico-político da soberania, para o âmbito dos aparelhos de Estado e das ideologias que o acompanham, deve-se orientá-la para o âmbito da dominação (e não da soberania), para o âmbito dos operadores materiais, das formas de sujeição, dos usos e das conexões dos sistemas locais dessa sujeição e para o âmbito, enfim, dos dispositivos de saber. (FOUCAULT, 2000, p. 40).

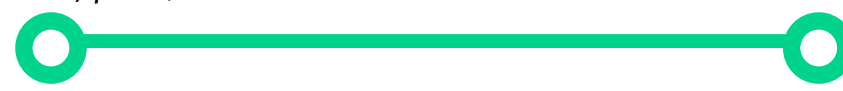

As estatísticas constituíram-se em ferramentas de esquadrinhamento e monitoramento das regularidades da população, colaborando no desbloqueio da arte de governar, senão vejamos:

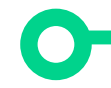

[...] se a estatística tinha, até então, funcionado no interior do quadro administrativo da soberania, ela vai revelar pouco a pouco que a população tem uma regularidade própria: número de mortos, de doentes, regularidade de acidentes, etc.; a estatística revela também que a população tem características próprias e que seus fenômenos são irredutiveis aos da família: as grandes epidemias, a mortalidade endêmica, a espiral do trabalho e da riqueza; revela finalmente que através de seus deslocamentos, de sua atividade, a população produz efeitos econômicos específicos.

Ao permitir a quantificação dos fenômenos próprios à população, revela-se uma especificidade irredutivel ao pequeno quadro familiar, qual seja a família como modelo de governo vai desaparecer.

Em contrapartida, o que se constitui nesse momento é a família como elemento no interior da população e como instrumento fundamental. (FOUCAULT, 1992, p. 288).

Se o olhar está no poder, deve-se, então, considerá-lo como uma rede produtiva que atravessa todo o corpo social e que depende do acúmulo de saber mediante métodos de 
observação e vigilância, procedimentos de pesquisa, aparelhos de verificação (ADORNO, 1991).

Significa dizer que, se as estatísticas são um dos mecanismos utilizados na vigilância da população e vale considerar que a lógica de sua produção responderia à incorporação deste tipo de ferramenta entre as estratégias para controlar as ações do Estado.

As estatísticas deveriam, portanto, assumir papel de relevância nas estratégias de controle social. Assim, é de se considerar, a perspectiva foucaultiana de abordagem das estatísticas em que se está falando da possibilidade de uma taxionomia e do uso e da interpretação que dela é feita.

Para Foucault, a palavra-chave desse processo é "interpretação", constituindose no elemento central do "saber", que, por sua vez, está no cerne do seu pensamento. Nesse diapasão o próprio Foucault (2000) nos elucida que "o que é próprio do saber não é nem ver nem demonstrar, mas, interpretar". (p. 55).

0 autor retrabalha, no plano microssociológico, questões clássicas do pensamento weberiano ao explorar os processosderacionalização, profissionalização e burocratização no desenvolvimento e funcionamento do modelo de justiça criminal e, por conseguinte, explorar o impacto dessas forças sobre o mundo social e as relações humanas (GARLAND, 1990).

Todavia, ao contrário de Weber, ele concebe o poder como oposto à soberania e dá destaque para os dispositivos de saber e para os usos e conexões dos sistemas locais de dominação (FOUCAULT, 2000).

\section{Algumas referências históricas no Brasil}

As primeiras referências e utilizações sistemáticas de estatísticas criminais identificadas no Brasil remontam ao ano de 1870; correspondendo ao período de burocratização, especialização e institucionalização do controle social, já fortemente influenciado pelos ideais liberais e pelo universo do direito (ADORNO, 1988).

Naquele período, foi promulgada a Lei no 2.033, de 20 de setembro de 1871 (regulamentada pelos Decretos 4.824, de 22 de novembro do mesmo ano, e 7.001, de 17 de agosto de 1878), que reformou a legislação existente até então e criou as figuras dos chefes de polícia, delegados, subdelegados e lhes atribuiu funções judiciárias, inclusive, a de formar a culpa e pronunciar em todos os crimes comuns, separando a polícia do judiciário e estabelecendo regras para a prisão preventiva, extensão da defesa no sumário da culpa, do habeas corpus e, em especial, criando a figura do Inquérito Policial.

A regulamentação dessa lei, no que diz respeito especificamente às estatísticas, foi feita através do Decreto no 7.001, de 17 de agosto de 1878, e precisou de 83 páginas para detalhar todas as possibilidades de variáveis e cruzamentos necessários ao atendimento da demanda do governo imperial.

Referido decreto faz distinção entre estatísticas policiais e judiciais e, dentro dessas últimas, caracteriza as estatísticas como criminal, civil, comercial e penitenciária.

Entre os informantes indicados para fazer cumprir essa legislação, destacam-se os chefes de polícia da Corte e das Províncias, que teriam a incumbência de preparar os mapas gerais de estatística policial e encaminhálos aos secretários de justiça e Presidentes de Província que, posteriormente, deveriam, juntos, enviá-los, até dezembro de cada ano, ao governo Imperial.

Isso fica explícito no artigo 25, do Decreto no 7.001, que determina que "os mapas gerais serão acompanhados de um relatório especial em que os chefes de polícia, os presidentes de províncias e o diretor geral da Secretaria de Justiça, comparando e apreciando as cifras constantes dos mesmos mapas, farão as considerações que julgarem convenientes 
sobre o estado moral da população e a administração da justiça".

Nesse aspecto, os dados apresentados por Fausto (2001), confirmam a constatação de que, em especial, os chefes de polícia estavam preocupados em fornecer informações de gestão e, o mais importante, prestar conta de procedimentos e ações até então empreendidas e que tinham no controle social o seu objetivo maior.

Os decretos do Império revelam que o legislador, talvez, influenciado pelo ideário do Estado Iluminista, dominado pela intenção planificadora e providencialista (HESPANHA, 1995), chegou a especificar 59 modelos diferentes de formulários de coleta de dados e a regulação dos prazos de apuração e retificação das informações, ou seja, para cada situação, havia uma orientação específica.

Existiam modelos para a apuração de crimes, hipotecas e transações comerciais diversas. Assim, ao que tudo indica, o Decreto no 7.001 constitui parâmetro de todas as estatísticas policiais, criminais e penitenciárias produzidas no Brasil a partir de então, ou seja, estabeleceu o que contar e como contar, entre outras coisas.

Sua leitura indica, entretanto, uma preocupação com o monitoramento estrutural do volume e movimento do crime e da criminalidade.

Infortunadamente, o acompanhamento conjuntural não estava imediatamente contemplado entre as preocupações nele presentes e, por conseguinte, aumentava, mesmo que indiretamente, o poder dos chefes de polícia e dos demais operadores da justiça, deixando-os livres para selecionarem os casos que seriam classificados nas grandes categorias das estatísticas.

\section{Cifras negras e definições do crime}

Derivado dessas preocupações, um novo conceito é desenvolvido e vai colaborar no desenho institucional das agências produtoras de estatísticas. Trata-se do conceito de "cifras negras" quepodem ser explicadas pelo fato de que somente uma parcela das vítimas comunica, aos distritos policiais, as ofensas criminais sofridas. Assim, pela falta de comunicação de fatos delituosos às autoridades competentes se estabelecem as "cifras negras", ou seja, "os casos que as forças de segurança pública não tomaram conhecimento".

Assim, a mudança no comportamento das pessoas, através da conscientização, poderia alterar os dados oficiais divulgados em relação à criminalidade, pois, se todos os fatos delituosos chegassem ao conhecimento das autoridades e fossem devidamente registrados, estaríamos mais próximos da "realidade".

Entretanto, "a despeito de todos os problemas indicados, as séries estatísticas oficiais indicam a tendência da criminalidade, sobretudo quando cobrem um período relativamente longo e, mesmo não correspondendo ao total de crimes cometidos, conseguem detectar a evolução e os movimentos dos crimes durante determinado período" (LIMA, 2002, p. 15-16).

O mais próximo do ideal seria que, além da incidência de crimes nos registros, fosse mensurado aquilo que chegava ao conhecimento oficial do Estado e, ainda, as percepções que os indivíduos tinham sobre crimes e criminosos.

Essa demanda acentuou a necessidade de constituição de "centros de cálculo", na medida em que exigia a associação de sofisticadas técnicas de tratamento estatístico de registros administrativos em conjunto com a produção de dados primários por meio de "surveys", questionários de pesquisa de opinião.

Nesse contexto, há a necessidade de pessoal especializado, afinal, sem os especialistas, um volume considerável de dados não se transformava em informações e 
conhecimento úteis à ação do Estado na área de justiça e segurança.

Essa "hiperespecialização" contribui, dessa forma, para deslocar o tema das estatísticas criminais do âmbito exclusivo dos operadores do sistema de justiça criminal esse não foi, totalmente, o caso do Brasil.

A segunda questão final diz respeito, exatamente, à limitação do método de pesquisa de vitimização acima exposta e que fala sobre a definição para crimes e criminosos que, até, merecerá o "status" de ciência - a criminologia - ao, no espírito positivista, estudar "a etiologia do comportamento criminoso e prever a dinâmica do crime e dos indivíduos que os cometem em função de leis causais" (VAZ, 1998, p. 32).

Os primeiros estudos sobre crime, entendido como um objeto específico, o focam como problema de legitimidade e justiça e serão produzidos pelos juristas, que avocarão o saber e a competência para lidar com suas causas e efeitos. É em torno do universo jurídico que o crime ganhará significado e passará a informar o conteúdo das estatísticas criminais.

No entanto, o que é crime não é um consenso entre tais profissionais e o embate de várias visões de mundo influenciará a adoção de uma ou de outra corrente jurídica. Nesse processo, a produção de estatísticas criminais tem de reconhecer que as categorias e classificações são socialmente construídas em cada localidade. Em outras palavras, a definição do que é crime e de quem seriam os criminosos é, usualmente, determinada pelas leis.

Todavia, quem poderá considerar fatos e indivíduos enquanto tais é uma discussão à parte. Significa dizer, assim, que em alguns lugares e momentos históricos, crimes e criminosos são atribuições do Poder Judiciário e, em outros locais e momentos, da polícia.

Numa terceira via, ainda, é no âmbito prisional que elas serão pensadas. A história da produção de estatísticas criminais no mundo e no Brasil revela, por conseguinte, que muitos foram os que optaram por coletar dados no âmbito do Poder Judiciário, que seria o único órgão de Estado com legitimidade para considerar um fato como crime. Os defensores dessa proposta alegam que se coletassem os dados em outros órgãos, como as polícias, fatos e indivíduos que posteriormente seriam desconsiderados ou inocentados, estariam sendo contados e isso seria equivocado.

Ao contrário, outro grupo via que dados criminais poderiam ser coletados também no âmbito policial, pois seriam de mais fácil acesso e temporalmente mais atuais, entretanto, será a partir do universo prisional que tais estatísticas terão o seu impulso maior e começarão a ser vistas como elementos de "governamentalidade".

Em termos históricos, a ênfase ora na polícia ora no judiciário como fontes de estatísticas criminais tende a revelar maior ou menor capacidade de usos e de publicização das informações existentes. E é, exatamente, dessas brechas que práticas aparentemente isoladas podem ganhar relevância e nos ajudar a compreender o sentido do controle social contemporâneo.

\section{Balanço das experiências estrangeiras em termos de estatística}

Se as estatísticas criminais foram definidas como sendo produtos do século XIX, como afirma Morrinson apud Brasil (2009), elas, no século XX, continuaram centrais nas disputas pelo domínio e controle dos elos de articulação de ações de pacificação social; de discursos de verdades que lutam pela prerrogativa de guiar as políticas públicas.

Os vários modelos estrangeiros analisados indicam que existe uma tensão permanente entre gestão e formas de "accountability" e as estatísticas funcionariam como chave interpretativa entre essas duas 
dimensões, sendo vistas como elementos centrais dos sistemas de informação das sociedades democráticas (United Nation, 2001).

Várias são as possibilidades de organização, mas o consenso histórico parece ser o de que as estatísticas servem melhor aos propósitos de governamentalidade quando integrantes de sistemas integrados de informação, que contemplam análises de registros administrativos e pesquisas de survey (vitimização, entre outras). Isso chega a ponto de que organismos multilaterais como a ONU (Organização das Nações Unidas) e organizações civis elaborarem planos para o desenvolvimento de sistemas de estatísticas da justiça criminal.

Muitas das experiências tratadas indicaram, ainda, que o pacto federativo é determinante para a configuração de modelos mais ou menos integrados de dados.

A ONU publica, desde 1980, anualmente,

um manual para desenvolvimento de tais sistemas e cuida de expor as várias arquiteturas possíveis para a organização de estatísticas - de agências independentes de produção a centros ligados às agências policiais e judiciais, passando por aspectos de linguagem, padronização de classificações e treinamento de pessoal (United Nations, 2001).

Fora isso, as Nações Unidas possuem uma Divisão de Estatísticas, ligada ao seu Conselho Econômico e Social, que fez aprovar, em 1993, princípios fundamentais para a produção de estatísticas oficiais em seus Estados membros, bem como orientações para as suas aplicações (United Nations, 2004). Já o Vera Institute of Justice, organização civil dedicada a discutir questões ligadas à segurança e à justiça, produziu, com suporte financeiro do Departamento de Desenvolvimento Internacional do Reino Unido, um guia para a construção de indicadores de performance na área de justiça que consigam medir o progresso de ações de segurança e justiça.

Nesse guia, as estatísticas criminais produzidas pelas agências oficiais têm função-chave e demonstram a crença na capacidade da informação, enquanto estoque de conhecimento e capital social, pode ser útil à democratização das instituições de justiça (Vera Institute, 2003).

Ainda no campo dos requisitos democráticos, outro fator de destaque é o que se pôde avaliar que países com maior tradição de acompanhamentos estatísticos de crimes e criminosos têm, nos seus Parlamentos, um espaço permanente para a apresentação e a discussão dos dados produzidos. A obrigatoriedade de apresentação de balanços e prestações de contas parece mudar a relação das instituições com as estatísticas e sua produção passa a ser alvo de atenção e poder. Esse movimento indica a força da dicotomia entre público e privado, entre controle público da ação estatal.

\section{USO DE INDICADORES DE AVALIAÇÃO DE DESEMPENHO E PRESTAÇÃO DE CONTAS DE RESULTADOS ALCANÇADOS: O CONTROLE CIENTÍFICO DA POLÍCIA}

A avaliação de resultados é inimiga da rotina e da indiferença, assim,quando se pensa na formulação de um coerente sistema de avaliação de desempenho policial e de gestão pública policial, algumas questões devem permear a cabeça de pesquisadores e gerentes policiais, sob pena de comprometer o próprio modelo que se quer introduzir e de incentivar resultados contrários ao que se objetiva a priori. (DURANTE; ZAVATARO, 2007).

Nessa esteira, algumas questões centrais devem estar presentes: 0 que se quer avaliar? Como avaliar? Quais os beneficios que isso trará? Quem irá avaliar? 
Atualmente, pode-se inferir que as organizações modernas, sobretudo com advento de instrumentos de informatização, já possuem condições de avaliar objetivamente suas ações, desde que, é claro, tenham de antemão uma boa metodologia de coleta e de análise de dados.

Entretanto, restam inúmeras dúvidas a respeito do que se quer avaliar em termos das ações e da gestão das organizações policiais, posto que sua missão e seu produto final sejam objetos de controvérsias, tanto por pesquisadores quanto por policiais que se debruçam no estudo das polícias. Dependendo de uma ou outra posição, ter-se-ão sistemas diferentes de avaliação e, pior, capazes de levar a efeitos contraproducentes. Por este motivo, um sistema de avaliação policial deve ser construído tendo por base os inúmeros fatores que permeiam as instituições policiais, os limites da avaliação e os riscos inerentes à formulação de indicadores impróprios e mal construídos, bem como deve ser conduzido pela discussão de inúmeros atores, buscando a adesão da necessidade premente de um modelo de gestão eficiente, efetivo e eficaz, inclusive contando com a participação e com a contribuição dos mais diversos níveis hierárquicos das instituições policiais, ou seja, não imposto de cima para baixo. (DURANTE; ZAVATARO, 2007).

A definição do que se quer avaliar está relacionada diretamente à definição da missão institucional da polícia e, neste aspecto, não há consenso sobre qual seja a verdadeira missão das polícias. Páginas e mais páginas estão sendo preenchidas a esse respeito, sem que, no entanto, esta discussão esteja perto de seu termo.

Nessa seara, se pode inferir dos trabalhos mencionados duas grandes linhas referentes aos debates acerca da missão das polícias. A primeiracaracteriza o trabalho policial a partir do seu aspecto coercitivo, como instituição encarregada de aplicar a lei, podendo utilizar, dentro de certos limites, a força física e o constrangimento, caso sejam necessários para o cumprimento de seu dever. Outro aspecto desta mesma face intelectual diz respeito à crença de que a missão fundamental da polícia é a luta contra o crime.

Para a segunda linha de pensamento, o trabalho policial, marcado principalmente por um grande poder discricionário, ultrapassa os aspectos meramente repressivos da atividade, abarcando uma série de atividades que os policiais desenvolvem em campo e de caráter muitas vezes preventivo e assistencialista, aspectos que não podem ser descartados ou negligenciados quando da análise da função multifacetal das polícias nas sociedades modernas.

Assim cabe questionar: qual é a missão da polícia? Se o que se objetiva é avaliar a organização, buscando-se indicadores pertinentes, não se pode resumir a análise em algo que seria a essência do serviço policial, mas sim, deve-se construir um sistema coerente de avaliação que abranja as diversas atividades desenvolvidas pelas instituições policiais, de modo a aperfeiçoar a gama de atividades que desenvolve rotineiramente, possibilitando assim o monitoramento e a reavaliação das suas ações. Diretamente ligada à questão da missão da polícia, encontra-se a delicada questão dos meios para o cumprimento de seus objetivos. (DURANTE; ZAVATARO, 2007).

Nesse aspecto, fica evidente que em um Estado Democrático de Direito, a polícia - e todaa Administração Pública - deve se basear no princípio da legalidade e no respeito aos direitos humanos consagrados constitucionalmente. Desse modo, não se pode, por exemplo, preconizar o desrespeito às leis em nome do combate à criminalidade.

A missão policial deve, a todo o momento, estar revestida da licitude e da proporcionalidade dos meios e fins, exigindo, com isso, que uma das dimensões de avaliação das organizações abarque indicadores de uso da força e de letalidade das polícias.

Não apenas a missão da polícia se 
revela controvertida e sem um consenso por parte de pesquisadores e de policiais, mas também a discussão em torno dos objetivos das ações das polícias. Qual é, neste sentido, o resultado das ações das polícias? Reduzir crime, esclarecer crimes, promover segurança pública, promover assistência, promover satisfação das vítimas de crimes? E o que é satisfação? É possível exigir isso da polícia? No mais, o tempo de resposta às chamadas solicitadas pode ser considerado medida de satisfação do público ou é apenas o processo da ação e não o produto? Qual seria o impacto das estratégias de resolução de problemas e de policiamento comunitário, em contraposição às estratégias tradicionais? E quais seriam os indicadores para cada estratégia? Como podemos ver, dúvidas e mais dúvidas restam no que concerne ao trabalho das polícias. Por esta razão a literatura é uníssona em se adotar o termo "impacto" das ações, pois embora seus objetivos e resultados atendidos possam estar definidos, somente um sistema de avaliação pertinente pode mensurar o impacto das ações empreendidas.

Mais do que se ater a indicadores tradicionais, que são fáceis de medir, o que se busca com um modelo apropriado é a avaliação do desempenho e a busca por estratégias capazes de oferecer um melhor serviço policial. (ZAVATARO, ca. 2008). 2008):

No entendimento de Zavataro (ca.

Resta, assim, a curiosidade de se analisar quais as melhores estratégias de policiamento em termos de incidência criminal e medo do crime.Evidências sugerem que o policiamento voltado para a comunidade, o policiamento de resolução de problemas e a participação política de grupos comunitários nos assuntos atinentes à segurança pública podem contribuir para a melhoria do serviço prestado pelas polícias e, neste caso, indicadores de encontros com a polícia, qualidade do serviço prestado, atitude da mídia em relação à polícia, entre outros, devem permear o espectro de um modelo de avaliação.

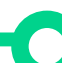

Acerca desse viés policial é pertinente destacar que:

é completamente errôneo atribuir exclusivamente às Polícias Militares ou às demais forças de segurança pública (polícias) as mazelas atuais vividas pela segurança pública, afinal, conforme assevera o texto constitucional, a segurança é uma "responsabilidade de todos". (NASCIMENTO; NASCIMENTO, 2018, p. 94).

Outra dificuldade diz respeito ao que se entende por satisfação com o trabalho policial. Satisfação é ela própria, o produto que se espera do trabalho da polícia ou, ao contrário, o que se espera é a resolução da situação e do problema demandado? O que importa é o resultado ou o meio utilizado para o atingimento do resultado?

Destaque-se que 0 interesse na medição da satisfação com o trabalho exercido é significativo, pois denota a boa ou má imagem que a instituição vai ter por aqueles que buscam o seu serviço.

No campo policial tal aspecto é ainda um grande desafio, principalmente em relação a determinadas parcelas sociais, razão pela qual deve ser percebido como um indicador de resultado, embora não o único.

Outra ordem de dificuldades diz respeito à construção de indicadores pertinentes de avaliação. Assim, se o que se quer é avaliar atividade ao invés do resultado ou este ao invés daquela, diferentes medidas serão adotadas em uma ou outra dimensão. 0 mais adequado é conjugar indicadores de processo e indicadores de produto ou, apropriando-se da terminologia da ciência política, inputs e outputs.

Como assinala Cano (s.d., p. 08) ao tratar sobre o tema:

[...] cualquier evaluación de impacto de una institución debe contemplar, prioritariamente, los resultados finales obtenidos, y no simplemente los esfuerzos desarrollados para conseguirlos; de qué serviría tener más agentes patrullando en la calle si, al final, esto no 
consigue disminuir la inseguridad reinante. Así, las actividades médio deberían ser consideradas sólo en la medida en que consiguiesen sus objetivos. Vistas las cosas de esta forma, ¿no sería más simple medir los resultados y olvidarse de los medios?

Outro ponto importante a ser destacado é não deixar que o sistema de indicadores de desempenho ganhe a reputação de um processo extremamente burocrático e de cunho meramente punitivo. Espera-se que um modelo de avaliação policial sirva como incentivo à mudança cultural no âmbito das organizações policiais, principalmente nos quesitos atinentes à prestação de contas, à accountability, à transparência, à gestão e aos resultados das ações públicas. Devese construir um sistema que obtenha a legitimidade por parte de todos os niveis policiais, principalmente por parte das lideranças, e que seja visto, não como um instrumento de punição, mas como um instrumento de promoção dos bons policiais. (DURANTE; ZAVATARO, 2007).

Cabe fazermos uma breve abordagem dos instrumentos comumente utilizados para efetivação das avaliações de desempenho policial. O aconselhável, para quem quer desenvolver um sistema confiável de avaliação policial, é conjugar quantos instrumentos forem necessários para qualificar as avaliações efetivadas.

Nesta esteira Durante e Zavataro (2007) apresentam algumas características dos instrumentos utilizados em avaliações de desempenho, senão vejamos:

Dados administrativos produzidos pelas próprias organizações policiais: tais dados podem aferir medidas como taxas de crimes registrados, taxas de esclarecimento e elucidação de crimes, taxas de morte, ferimentos e danos em vias públicas, aumento e diminuição de denúncias contra policiais, aumento e diminuição da violência e letalidade policial, uso apropriado de recursos públicos nas operações e atividades da polícia, entre outros.

Pesquisas de vitimização: destas pesquisas é possivel extrair um conjunto de indicadores de avaliação, tais como taxas de vitimização, registros de mudança dos niveis de medo do crime e sensação de segurança pessoal, registros de mudança nas estratégias de autodefesa por parte dos indivíduos, aumento ou diminuição da utilização de parques ou espaços públicos, satisfação e grau de confiança com o serviço da polícia, taxas de subnotificação de violência e corrupção policial, entre outros.

- Dados econômicos: tendo em vista que a vitimização refletem em muito a qualidade de vida e o desenvolvimento social e econômico de determinadas áreas, é possivel extrair dos dados econômicos uma aproximação em termos das respostas ao problema da violência por parte das organizações policiais. Assim, entre alguns exemplos, os dados de valorização e desvalorização de imóveis em determinadas regiões e dados de aceleração e desaceleração de economias locais.

Surveys Focais: a grande vantagem dos surveys focais é não serem tão caros quanto às pesquisas de vitimização. Como exemplos de surveys focais, temos entrevistas realizadas com funcionários hospitalares, representantes de ONGs e de associações comerciais, representantes comunitários, dentre outros.

Sistemas de despachos de ocorrências policiais: embora façam parte dos dados administrativos, devem ser considerados à parte pela sua importância enquanto fonte de indicadores de avaliação. Por meio das informações advindas das demandas do número 190 (Brasil) ou 911 (EUA), é perfeitamente cabivel buscar fontes como o tempo de atendimento, natureza das solicitações, o que as pessoas esperam da polícia, entre

outros indicadores. (p. 86)

Buscando trazer subsídios práticos para a nossa discussão, terminaremos esta seção fazendo a descrição de um sistema de indicadores de desempenho, denominado Controle Científico da Polícia, utilizado pela Polícia Militar de Minas Gerais (PMMG) nestes últimos 10 anos. Constitui um bom exemplo do progresso alcançado na evolução da gestão dos órgãos de segurança pública no Brasil, conforme quadro abaixo, senão vejamos':

\begin{tabular}{|l|l|}
\hline Dimensão & Indicadores \\
\hline Pessoal & 01. Absenteísmo \\
\hline
\end{tabular}

1 DURANTE, M. O.; ZAVATARO, B. p. 86. 


\begin{tabular}{|c|c|}
\hline $\begin{array}{l}\text { Inteligência/Infor- } \\
\text { mações }\end{array}$ & 02. Policiamento Velado \\
\hline \multirow[t]{5}{*}{$\begin{array}{l}\text { Planejamento das } \\
\text { Operações }\end{array}$} & $\begin{array}{l}\text { 03. Emprego do Policiamento a } \\
\text { Pé em Áreas Comerciais }\end{array}$ \\
\hline & 04. Atendimento Comunitário \\
\hline & $\begin{array}{l}\text { 05. Relacionamento Comuni- } \\
\text { tário }\end{array}$ \\
\hline & 06. PROERD \\
\hline & $\begin{array}{l}\text { 07. Eficiência das Patrulhas de } \\
\text { Prevenção Ativa }\end{array}$ \\
\hline \multirow[t]{2}{*}{ Apoio Logistico } & 08. Emprego de Viaturas \\
\hline & $\begin{array}{l}\text { 09. Indisponibilidade de Via- } \\
\text { turas }\end{array}$ \\
\hline Comunicação & $\begin{array}{l}\text { 10. Opinião Pública (Jornalismo } \\
\text { Comparado) }\end{array}$ \\
\hline \multirow[t]{2}{*}{$\begin{array}{l}\text { Estatatística e } \\
\text { Geoprocessamento }\end{array}$} & $\begin{array}{l}\text { 11. Desempenho Operacional } \\
\text { da Unidade Policial com Res- } \\
\text { ponsabilidade Territorial }\end{array}$ \\
\hline & $\begin{array}{l}\text { 12. Desempenho Operacional } \\
\text { de Unidade Tático Móvel }\end{array}$ \\
\hline \multirow{4}{*}{$\begin{array}{l}\text { Estratégias e } \\
\text { Pesquisas }\end{array}$} & 13. Capacidade Técnica \\
\hline & 14. Capacidade Tática \\
\hline & 15. Qualidade do Atendimento \\
\hline & $\begin{array}{l}\text { 16. Indicador da Eficiência em } \\
\text { Controle Científico da Polícia. }\end{array}$ \\
\hline
\end{tabular}

Como já destacado anteriormente, observa-se que os parâmetros utilizados pela PMMGpara avaliação ainda carecem de uma efetiva abertura e de um espaço de discussão com a sociedade para a definição do papel e da missão da polícia.

Por meio dessa metodologia, o desempenho das Unidades Operacionais da Polícia Militar de Minas Gerais, do Comando da Capital, é avaliado em função de sete dimensões: pessoal, inteligência/informações, planejamento das operações, apoio logístico, comunicação organizacional, estatística/ geoprocessamento e estratégias/pesquisas.

Ressalte-se que é um processo de avaliação que prioriza a criação de resultados coletivos, ou seja, o bom ou o mal comportamento de um profissional da unidade operacional traz resultados para todos os profissionais da mesma unidade operacional, fazendo com que cada profissional passe a monitorar não apenas o seu comportamento, mas também o comportamento dos membros da sua equipe de trabalho.

Referido processo envolve continuamente, tanto a sistematização de informações administrativas das unidades operacionais, quanto a coleta de informações junto à mídia e a própria população que procurou à polícia (clientes do serviço prestado).

\section{GEOPROCESSAMENTO AUXILIANDO A SEGURANÇA PÚBLICA NO MAPEAMENTO DA CRIMINALIDADE}

As geotecnologias têm ocupado, nas últimas décadas, um importante espaço entre as ferramentas computacionais no tratamento de informações em que a localização geográfica é um importante atributo.

Atualmente, a capacidade de coletar, interpretar e gerar informação de forma eficiente e eficaz é um dos requisitos mais importantes para o crescimento e organização da sociedade, pois num mundo cada vez mais capitalista, em que a agilidade e a consistência da gestão pública e ou privada é fator decisivo e de grande importância nas tomadas de decisões. Assim, diversos órgãos e instituições públicas e privadas têm encontrado no geoprocessamento respostas para diversos problemas, que antes era impossivel devido a grande demanda de dados para um tempo cada vez mais limitado.

Para além, necessitam manter os recursos existentes e, ao mesmo tempo, agilizar os processos de gerenciamento, análise e distribuição de novos dados. Isso inclui desde os dados relacionados ao registro de imóveis e propriedades, como também dados provenientes de concessionárias de água e 
esgoto, energia elétrica, gás e telecomunicação, proteção ambiental, planejamento agrícola, meteorologia, geomarketing até os relativos às áreas de saúde e segurança pública, todos incorporando tecnologia geoespacial, permitindo aos usuários executar procedimentos complexos assegurando 0 desenvolvimento e gerenciamento de toda a infraestrutura (SILVA, 2003).

O uso de tecnologia de análise espacial, combinada com dados socioeconômicos e ambientais, constitui uma poderosa alternativa para a instrumentalização de políticas públicas de combate à criminalidade urbana. Neste contexto, a apresentação de uma tecnologia integradora e sistemática de captura, armazenamento, consulta e análise de dados referentes à criminalidade urbana, é a finalidade principal desta ferramenta, abrindo um leque de visão para as autoridades policiais, demonstrando o uso do geoprocessamento como uma alternativa de alto valor para o tratamento de questões de segurança pública.

\section{Geoprocessamento segurança pública mapeamento da criminalidade}

A necessidade de possuir, atualizar e controlar a informação é fundamental em qualquer operação policial. Consequentemente, utilizar uma melhor tecnologia que atenda as demandas e os anseios da sociedade, produz aumento significativo da eficiência na segurança pública. A complexidade dos problemas sociais na atualidade nos conduz para uma ótica cada vez mais comprovada: não basta apenas aparelhar as operações policiais com armamentos, viaturas e efetivo sem que disponibilizem ferramentas que permitam a otimização, de forma global,dos recursos disponíveis.

De acordo com Vasiliev (1996) citado por Harries (1999) "os crimes ocorrem - tudo ocorre - tanto no tempo quanto no espaço". A utilização intensiva de tecnologias de informação espacial tem promovido uma verdadeira revolução silenciosa nas polícias de todo o mundo (REULAND, 1997).

As Geotecnologias vêm ocupando cada vez mais espaços nos Sistemas de Segurança Pública, uma vez que a informação espacial da violência é fator decisivo para o controle e combate a criminalidade urbana. Sistemas de informação têm servido para a detecção de padrões e regularidades de maneira a dar suporte a atividades de policiamento, bem como para prestar contas à comunidade sobre problemas relativos a segurança (BUSLIK; MALTZ, 1998).

O mapeamento exerce um importante papel no processo de investigação, análise e apresentação de dados sobre a violência, no entanto, suas múltiplas capacidades devem ser consideradas em todo o processo de aquisição de dados brutos à geração de informação consistente no âmbito tecnológico. Um mapa eficiente é o resultado de todo um processo em que relatórios policiais geoprocessados são introduzidos num banco de dados e finalmente transformados em símbolos passíveis de interpretação.

A representação visual facilita a definição de estratégias para enfocar ações nas áreas mais problemáticas. Nesse contexto, a geocodificação se torna fundamental para o mapeamento da criminalidade, uma vez que essa técnica é, na atualidade, a forma mais utilizada para introduzir dados sobre a violência em um SIG (Sistema Integrado de Geoprocessamento), afinal, os crimes ocorrem em determinado local e são registrados através de endereço ou alguma referência espacial.

Há tempo, o mapeamento e monitoramento da violência é parte integrante da análise criminalística. O mapeamento da criminalidade consistia em uma representação destacada dos crimes ocorridos em dada 
região. Os mapas produzidos eram muitos úteis para a "análise criminal", por identificarem o local onde os crimes aconteciam, porém,suas limitações eram bastante significativas.

Os mapas produzidos até então, eram estáticos, ou seja, não havia possibilidades de uma análise investigativa de manipulação e monitoramento de contínuo dos dados, além da dificil leitura e armazenamento.

Nesse sentido, especialistas afirmam que para se confeccionar um único mapa, se podia ocupar áreas superiores a 200 metros quadrados o que, demandariaváriosmeses para a sua conclusão; sem contar com a atualização rotineira (HARRIES, 1999).

Contudo, os mapas com destaques ainda são utilizados, pois, suas escalas permitirem uma boa visualização de toda uma jurisdição/ circunscrição, além de representarem um baixo custo e a desnecessidade de emprego de pessoal com qualificação específica.

Hodiernamente, 0 mapeamento da criminalidade pode ser realizado por computação gráfica, utilizando-se ícones e símbolos para demonstraçãodo local e do tipo de crime numa determinada área de atuação policial.

Nesse contexto e em termos locais, a Polícia Militar de Roraima (PMRR) faz utilização do sistema CIOPS CAD, que se trata de uma ferramenta tecnológica em que são registradas inúmeras informações relevantes, tais como: local da ocorrência (endereço, ponto de referência etc.), nome e telefone do solicitante, horário da chamada, horário de despacho da equipe (viatura), qual a equipe despachada (prefixo da viatura), tempo de início e de término da ocorrência atendida, qual a espécie de infração atendida e quais as providências adotadas, etecetera.

Assim, observa-se que a implementação da precitada ferramenta tecnológica é um avanço para a segurança pública roraimense, eis que, através dela há o fornecimento de estatísticas criminais, indo ao encontro dos ensinamentos apresentados anteriormente por Lima (2001), Martin (2001) e Cretella Júnior (1985), contribuindo assim, para uma melhor aplicação dos recursos policiais visando o enfrentamento da criminalidade conforme assertivas de Durante e Zavataro (2007), Reuland (1997), Silva (2003) entre outros.

\section{CONSIDERAÇÕES FINAIS}

Ao contrário do que mídia e opinião pública propagam, no Brasil, dados sobre crimese, mais residualmente, sobre criminosos foram produzidos e são preocupações desde o Império, contudo, o modelo brasileiro não conseguiu superar a dimensão do registro de fatos criminais e, por conseguinte, não toma a produção de dados pelas instituições de segurança e justiça como passo inicial para a utilização de informações e, a partir daí, para o acúmulo de conhecimento sobre os fenômenos sociais derivados das situações e casos descritos.

O Brasil não conseguiu avançar na montagem de um ciclo de produção e utilização de estatísticas criminais; não conseguiu coordenar politicamente o ciclo das informações sobre justiça e segurança públicas.

Infelizmente, o uso de estatísticas ainda não é visto como uma práticaincorporadana cultura organizacional das instituições de justiça criminal e de segurança pública.

Ainda permeiam nossos sistemas uma linguagem mais afeita à interpretação e adaptação do fato social à norma estabelecida, e, não ao emprego do policiamento na raiz do problema. O risco desse enfoque, tendo em vista o modelo fragmentado de organização da justiça criminal e da segurança pública do país, é que as iniciativas para a construção de centros de cálculo, centros de operações policiais, coordenação e sistemas de informações sejam reduzidas aos aspectos meramente tecnológicos envolvidos,ou seja, o conhecimento sobre o funcionamento do sistema de justiça criminal é obnubilado pela 
autonomização das formas jurídicas e de produção burocrática de dados e a produção de dados isolados de acompanhamentos estatísticos, cadastrais ou de inteligência torna-se suscetivel a críticas e a se consumir nos debates metodológico e tecnológico, distanciando-se da prática cotidiana da atividade policial e judicial.

Como resultado, há um reforço do processo em que os fenômenos da desordem, da criminalidade e da violência são absorvidos por lógicas pouco democráticas de resolução de conflitos e, mais, acabam reduzidos a pautas de determinados grupos - em especial os ligados ao universo jurídico e policial -, retroalimentado por práticas fragmentadoras da ação do Estado.

Nessa esteira, outros grupos e segmentos sociais tentam aproximar-se do debate sobre o tema, no entanto, são repelidos ou desqualificados em razão da alegação de um pretenso desconhecimento técnico da linguagem que organiza o funcionamento do sistema de justiça criminal brasileiro. Em suma, o problema da segurança pública e da justiça criminal é visto como predominantemente afeito ao universo jurídico e policial, cujas soluções devem ser pensadas preferencialmente pelos operadores jurídicos, que teriam a experiência do cotidiano para legitimar os seus atos.

Tal metodologia e forma de pensar afronta a sistemática constitucional, na medida em que o art. 144 da Magna Carta assevera que a segurança pública embora seja um dever do estado, é também direito e responsabilidade de todos.

O "controle social" não mais se encerra no domínio exclusivo dos aparelhos repressivos de Estado, deslocando, por conseguinte, o seu eixo de referência do poder político para o poder social, pelo qual estratégias de comunicação ganham espaço.

Não obstante algumas iniciativas locais que foram adotadas em São Paulo, Rio de Janeiro, Minas Gerais, no Brasil (Federação), ainda não existe uma política de integração e coordenação de informações em justiça criminal e segurança pública e, disso, nasce uma questão, qual seja, a não existência de "Centros de Cálculo", "Centros Integrados de Operações e Comunicações" que possuam a legitimidade para traduzir registros individuais em sínteses complexas e desenvolver métodos, técnicas e desenhos quantitativos que sejam aceitos como indicativos de estatísticas criminais objetivas e confiáveis.

Não se pode negar que há uma preocupação das autoridades, eis que recentemente foi criado o Sistema único de Segurança Pública (SUSP), através da Lei Federal no 13.675, de 11 de junho de 2018.

Referido Sistema visa integrar as instituições de segurança pública através de uma unidade de registro de ocorrência policial, além de procedimentos de apuração e o uso de sistema integrado de informações e dados eletrônicos.

Anteriormente ao SUSP tem-se que tanto os órgãos internos quanto as agências externas das instituições de justiça criminal não lograram legitimidade para se consolidarem como tais "centros", na medida em que, de um lado, reproduziram os fetiches sobre os dilemas de produção de informações e, por outro, enfrentam o fato de "centros policiais" serem recursos de poder e que, portanto, sua existência poderia significar um lócus privilegiado para uma eventual coordenação de tempos e de conteúdos de oferta e demanda de informações estatísticas e, consequentemente, um mecanismo de accountability das políticas públicas na área.

Em sintese, as estatísticas criminais brasileiras revelam que dados existem e fazem parte da história do sistema de justiça criminal do país, mas que eles não se transformam, mesmo após a redemocratização, em informações e, principalmente, em conhecimento aplicável à prevenção da criminalidade.

A realidade roraimense vem sendo 
modificada, no sentido de que atualmente os dados obtidos em ocorrências atendidas pela Polícia Militar já possuem tabulação estatística, o que, por sua vez, facilita o emprego dos recursos policiais de forma mais eficiente e eficaz.

De forma geral, pode-se afirmar que uma melhora significativa na Segurança Pública somente ocorrerá com a coordenação das várias iniciativas e com a articulação dos dados em sistemas de informação que contemplem tanto os produtores quanto os usuários de estatísticas criminais em amplitude Global/ Nacional, ou seja, tenham na transparência e na integração os pressupostos políticos que podem transformar as práticas cotidianas e o simulacro tecnológico do "Efeito Globalização" em políticas públicas efetivas de pacificação social.

Acrescentando que os sistemas de informação, nas polícias que têm implantado o SIG, têm servido para a detecção de padrões e regularidades de maneira a dar suporte a atividades de policiamento, bem como para prestar contas à comunidade sobre problemas relativos à segurança e de acordo com os resultados apresentados, conclui-se que a compreensão da dinâmica espacial das ocorrências criminais torna-se mais evidente à medida que as informações disponiveis são sistematizadas considerando de forma interrelacional as variáveis envolvidas.

Ressalta-se a importância da organização e sistematização das informações disponiveis, uma vez que para a obtenção de resultadossatisfatóriossobreaanálisecriminal com Geoprocessamento, as informações devem conter, além da qualificação do evento, o atributo de localização de forma mais detalhada possível.

Assim, o Geoprocessamento apresentase como uma ferramenta poderosa para a gestão e análise da criminalidade urbana, proporcionando que a implementação de políticas de segurança pública tenha uma atuação mais eficiente e eficaz, direcionadas de forma exata e não intuitiva, obtendo resultados significativos na tomada de decisão, garantindo uma melhor otimização das operações policiais.

\section{REFERÊNCIAS}

ADORNO, S. Cidadania e administração da justiça criminal.In DINIZ, E.; LOPES, J.; PRANDI, R. O Brasil no rastro da crise. São Paulo: Anpocs/Ipea/Hucitec, 1994. p.304-327.

ADORNO, S.A gestão urbana do medo e da insegurança: violência, crime e justiça penal na sociedade brasileira contemporânea. São Paulo: Universidade de São Paulo, Faculdade de Filosofia, Letras e Ciências Humanas. (Tese de livre docência).

BEATO, C. Determinantes da criminalidade em Minas Gerais. Revista Brasileira de Ciências Sociais, São Paulo, 13(37), jun, 1998.

BENEVIDES, M. V.; FISCHER, R. Respostas populares e violência urbana: o caso de linchamento no Brasil (1979-1982). In PINHEIRO, P. S. (org.) Crime, violência e poder. São Paulo: Brasiliense, 1983. p. 227-43.

BRASIL. Constituição da república federativa do Brasil de 1988. Disponível em: http:// www.planalto.gov.br/ccivil_03/constituicao/ constituicaocompilado.htm. Acesso em: 31/ ago/18.

Ministério da Justiça:coleção segurança com cidadania. Ano I, n.02. Brasília: 2009.

BUSLIK, M.; MALTZ, M. Power to the people: mapping and information

sharing in the Chacao Police Department, in Weisburd, David e McEwen, Tom (orgs.) Crime Mapping and Crime Prevention. 
Crime Prevention Studies. Criminal Justice Press,Monsey, New York, 1998.

CANO, I. La policía y su evaluación:propuestas para la construcción de indicadores deevaluación en el trabajo policial.Centro de Estudios para el Desarrollo, Área Seguridad Ciudadana Nueva de Lyon. Providencia, Santiago de Chile.

CERVO, A. L.; BERVIAN, P. A.; SILVA, R. Metodologia científica. 6. ed. São Paulo: Prentice-Hall, 2009.

CRETELLA JÚNIOR. J. Polícia e poder de polícia. Rio de Janeiro: Revista de Direito Administrativo, 1985.

DESROSIĖRES,A.La politique des grands nombres:histoire de la raison statistique. Paris, La Découverte, 1993.

DURANTE, M. O.; ZAVATARO, B. limites e desafios da evolução da gestãoem segurança pública: a importância do uso de indicadores de avaliação de desempenho. São Paulo em Perspectiva, v. 21, n. 1, p. 76-91, jan./jun. 2007.

FAUSTO, B. Crime e cotidiano. São Paulo: EDUSP, 2001.

FOUCAULT, M. Vigiar e punir: nascimento da prisão. Petrópolis: Vozes, 2000.

.Estratégia, Poder-saber. Rio de Janeiro: Forense Universitária, 1992.

GARLAND, D. Sociological perspectives on punishment.Crime and Justice, Vol. 14, 1991, p.115-165.

GIL, A. C. Como elaborar projetos de pesquisa.

5. ed. São Paulo: Atlas, 2010.

HACKING, I. The self-vindication of the laboratory sciences, in Pickering, Andrew. Science as practice and culture. Chicago: University of Chicago Press, 1992.
How should we do the history of statistics?In: GORDON e MILLER (orgs). The Foucault effect: studies In governmentality. Burchell Chicago: The University of Chicago Press, 1991.

HARRIES, K. Mapping crime: principle and pratice. Washington, DC: U. S. Department of Justice Office of Justice Programs, 1999.

HESPANHA, A. M. História de Portugal moderno: político-institucional. Lisboa: Universidade Aberta, 1995.

LAKATOS, E. M.; MARCONI, M.A. Fundamentos de metodologia científica. 5. ed. São Paulo: Atlas 2003.

LIMA, K. A polícia da cidade do Rio de Janeiro: seus dilemas e paradoxos. Rio de Janeiro. Polícia Militar do Rio de Janeiro, 1994.

LIMA, M. A. Confiança na Polícia: experiência, informação e reflexão como fatores intervenientes. Belo Horizonte: Fundação João Pinheiro, 2003. Mestrado em Administração Pública.

LIMA, R. S. Acesso à justiça e reinvenção do espaço público: saídas possíveis de pacificação social. Revista São Paulo em Perspectiva, São Paulo, 11(3): jul-set, 1997. p. 86-91.

MANZO, A. J.Manual para la preparación de monografias:una guia para presentar informes y tesis. Buenos Aires: Humanitas, 1971.

MARTIN, J. Is the self a kind of undestanding?Vancouver:Journal for the theory of social behavior, 2001.

MINAS GERAIS, Polícia Militar. Diretriz para a produção de serviços de segurança pública no 01/2003-CG: emprego da Polícia Militar de Minas Gerais. Belo Horizonte: Comando-Geral, 2003. 
Instrução n 05/2005-8a RPM: organiza e normatiza a Nova Malha Protetora da Polícia Militar sobre o Município de Belo Horizonte. Belo Horizonte: Comando de Policiamento da Capital, 06 de setembro de 2005.

Instrução no 01/2005-8a RPM: implanta e disciplina a avaliação de desempenho de subunidades e serviços operacionais. Belo Horizonte: Núcleo de Estratégias e Pesquisas/Comando de Policiamento da Capital, 06 de setembro de 2005.

Instrução $n^{\circ}$ 02/2004-8a RPM: disciplina o planejamento e a repressão integrada à criminalidade violenta pela Polícia Militar e Polícia Civil, nas Áreas Integradas de Segurança Pública do Município de Belo Horizonte. Belo Horizonte: Núcleo de Estratégias e Pesquisas/Comando de Policiamento da Capital e 10 Departamento de Polícia Civil, setembro de 2004.

.Instrução no 01/2004-8a RPM: cria e disciplina as Patrulhas de Prevenção Ativa, para emprego no Município de Belo Horizonte. Belo Horizonte: Núcleo de Estratégias e Pesquisa/Comando de Policiamento da Capital, julho de 2004.

NASCIMENTO, N. R. B.; NASCIMENTO, P. R. T. B. Policiamento ostensivo como ferramenta de prevenção a ilícitos. Disponível em: <https:// casademakunaima.uerr.edu.br/index.php/ home/issue/view/1/ISSN\%200NLINE\%3A\%20 2595-5888>, acessado em: 03/set/18.

NECKER, S. C. Os manuscritos Gertrudes. Madson: Universidade de Wisconsin.

REULAND, M. M.Information management and crime analysis. Washington, DC: Police Executive Research Forum, 1997.
SCHWARTZMAN, S. A política dos grandes números. Disponível em: <https://archive. org/stream / PoliticaDosGrandes Numeros ndesNumeros1995SimonSchwartzman\#page/ n0>, acessado em: 02/set/18.

SILVA, A. L. Avaliação de resultados das ações preventivas de Polícia Comunitária em Belo Horizonte: reflexões a respeito da aplicação de um modelo. Belo Horizonte: Academia de Polícia Militar; Fundação João Pinheiro, 2004.

SILVA, B. F. A. Criminalidade urbana violenta: uma análise espaço-temporal dos homicídios em Belo Horizonte. Monografia (Graduação em Ciências Sociais) - UFMG, Belo Horizonte. 2001.

SILVA, D. P. Vocabulário jurídico. 19. ed. Rio de Janeiro: Forense, 2002.

SILVA, J. Controle da criminalidade e segurança pública na nova ordem constitucional.Rio de Janeiro: Forense, 2008.

UNITED NATIONS. Manual for the development of a system of criminal justice statistics. New York: United Nations, 2001.

Fundamental principles of official statistics. New York: StatisticsDivison, United Nations, 2004.

Aplicación de los princípios fundamentales de las estadísticas oficiales. Comisión de Estadística do Consejo Económico y Social de La Naciones Unidas. Nova Iorque, 2004.

VASILIEV, O. V. Optimization methods (advanced series in mathematical science and engineering). Nova lorque: World Federation Pub Inc, 1996.

VAZ, M. J. Crime e sociedade: Portugal na segunda metade do século XIX.Oieras: Celta, 1998. 
VERA INSTITUTE OF JUSTICE. Measuring progress toward safety and justice: a global guide to the design of performance indicators across the justice sector. Nov/2003.

ZAVATARO, Bruno.Da reforma do setor público à avaliação de desempenho das organizações policiais: propostas, limites e desafios.c.a. 2008, S.l.:S.n. 